\title{
Sarcoma de Kaposi y enfermedad de Castleman multicéntrica VHH-8 positivo - VIH Negativo Un subgrupo etiológico
}

\author{
Kaposi's sarcoma and multicentric Castleman's \\ disease VHH-8 positive - HIV negative \\ An etiological subgroup
}

\author{
Luis Antonio Rodríguez, Gener Mahaht Rada, Luis Antonio Salazar, \\ Rita Magola Sierra • Cartagena (Colombia)
}

\section{Resumen}

El sarcoma de Kaposi y la enfermedad de Castleman multicéntrica/virus herpes humano-8 positivo/virus de la inmunodeficiencia humana negativo representan un subgrupo etiológico dentro del espectro clínico de las enfermedades asociadas al virus herpes humano- 8 positivo, inicialmente fueron consideradas dos entidades aisladas. El virus tiene un papel protagónico por su tropismo por el tejido linfoide y su potencial oncogénico. La presencia de sarcoma de Kaposi y enfermedad de Castleman multicéntrica/virus herpes humano-8 (VHH-8) positivo/virus de la inmunodeficiencia humana (VIH) negativo sugiere la posibilidad de una deficiencia inmunológica subyacente. Se presenta un caso de una mujer de 67 años de edad con dermatosis en extremidades de curso indolente y aparición posterior de múltiples adenomegalias, esplenomegalia además síntomas sistémicos. Se destaca el abordaje diagnóstico, la coexistencia de dos enfermedades etiológicamente ligadas al virus herpes humano-8, sin asociación de inmunosupresión.

Palabras clave: sarcoma de Kaposi, hiperplasia de ganglio linfático gigante, herpesvirus humano 8, VIH.

\begin{abstract}
Kaposi's sarcoma and Castleman's disease Multicentric / Human Herpes Virus-8 positive / Human Negative Immunodeficiency Virus represent an etiological subgroup within the clinical spectrum of diseases associated with Human Herpes- 8 positive virus that were considered two isolated entities. The virus plays a leading role due to its tropism for lymphoid tissue and its oncogenic potential. The presence of Kaposi's sarcoma and multicentric Castleman's disease / human herpes virus-8 (VHH-8) positive / Human immunodeficiency virus (HIV) negative suggests the possibility of an underlying immune deficiency. The case of 67 -year-old woman with dermatosis in extremities of indolent course and subsequent appearance of adenomegalies, splenomegaly in addition to systemic symptoms is presented.The diagnostic approach and the coexistence of two diseases etiologically linked to the Human Herpes Virus-8, without association of immunosuppression stand out.
\end{abstract}

Key words: Kaposi's sarcoma, giant lymph node hyperplasia, human herpesvirus 8, HIV
Dr. Luis Antonio Rodríguez Arrieta, Dr. Gener Mahaht Rada: Residentes de Medicina Interna, Universidad de Cartagena; Dr. Luis Antonio Salazar Montaña: Universidad Autónoma de Bucaramanga UNAB, FOSCAL; Dra. Rita Magola Sierra: Coordinadora Posgrado Medicina Interna, Universidad de Cartagena. Cartagena (Colombia).

Correspondencia: Luis Antonio Rodríguez Arrieta, Cartagena (Colombia).

E-mail: luismd0507@gmail.com

\section{Introducción}

El sarcoma de Kaposi (SK) está asociado a la presencia del VHH-8 en 99\% de los casos y por esa razón fue denominado como virus herpes del sarcoma de Kaposi (VHSK) por Chang y colaboradores desde 1994 (1) La estrecha relación de SK y enfermedad de Castleman multicéntrica (ECM) en enfermos con VIH condujo al descubrimiento de la asociación del VHH-8 con este trastorno linfoproliferativo (2).
Posteriores investigaciones condujeron al descubrimiento del espectro de la infección por VHSK que puede conducir al desarrollo simultáneo de otras enfermedades asociadas en un mismo sujeto en presencia o no de inmunosupresión (3).El VHH8 se clasifica en la familia de gammaherpesvirus junto con el virus de Epstein-Barr (VEB) por su tropismo por el tejido linfoide y su potencial oncogénico se relaciona con la proliferación de células B infectadas, la desregulación de 
la interleucina 6 humana (IL-6), la interleucina 10 (IL-10) y la producción de interleucina 6 viral (vIL-6) (1).

El SK fue descrito por Moritz Kaposi en Viena en 1872 y la enfermedad de Castleman (EC), tambien llamada hiperplasia linfoide angiofolicular, por B. Castleman en 1956(3). Ambas entidades se diagnosticaron por criterios anatomopatológicos y por muchos años se consideraron dos entidades aisladas. El SK tiene fenotípicamente 4 variantes: la clásica que afecta en su mayoría a hombres de origen mediterráneo de ascendencia judía, ocasionando lesiones cutáneas indolentes predominantemente en miembros inferiores, la africana más agresiva compromete piel y vísceras y afecta a la población subsahariana, la epidémica y la iatrogénica asociada a inmunosupresión por infección por VIH o por medicamentos inmunosupresores (1).

La EC desde la serie inicial de casos descritos como una lesión mediastinal que simulaban un timoma se centró en los hallazgos anatomopatológicos, y bajo este epónimo se reúne un heterogéneo grupo de trastornos linfoproliferativos no clonales, infrecuentes. Se han descrito tres tipos histológicos con varias formas clínicas según: la forma de presentación, el sustrato histológico y las enfermedades asociadas. Actualmente la EC incluye al menos cuatro enfermedades diferentes: la EC unicéntrica (ECU), la ECM-VHH-8 positivo/VIH positivo; la ECM- VHH-8 positivo/VIH negativo y la ECM idiopática (4).

El SK, ECM y el LPCS están fuertemente relacionadas con el VHH-8, en sujetos que presentan al menos una de las tres anteriores patologías las tasas de prevalencia de serologías positivas para VHH-8 pueden aumentar hasta $100 \%$ (5). La coexistencia de la ECM y SK se produce en hasta un $82 \%$ de los casos $(3,5)$. La presencia de SK y ECM VHH-8 positivo/VIH negativo sugiere la posibilidad de una deficiencia inmunológica subyacente (4). La importancia de presentar el caso es destacar el abordaje diagnóstico y la coexistencia de dos enfermedades etiológicamente ligadas VHH-8, SK y ECM, en una mujer VIH negativo y sin riesgo de inmunosupresión.

\section{Caso clínico}

Mujer de 67 años con antecedente de hipertensión arterial e insuficiencia cardiaca. Con enfermedad actual de cinco meses de evolución que inició tos seca acompañada de expectoración amarillenta, hiporexia, astenia, mialgias y fiebre episódica de patrón continuo, sin hemoptisis. El estudio para enfermedades infecciosas mostró baciloscopía seriada negativa y cultivo de esputo en medio líquido positivo para Mycobacterias sp.; recibió tratamiento antituberculoso de primera línea suspendido por hepatitis tóxica como evento adverso que mejoró con la suspensión de los medicamentos. En la visita de control manifestó persistencia de fiebre, pérdida involuntaria de $9 \mathrm{~kg}$ peso con palidez mucocutánea, adenomegalias múltiples de 1-2 cm, superficiales, firmes de bordes regulares, móviles, no dolorosas localizadas en triángulo cervical anterior y supraclavicular, región axilar e inguinal bilaterales y esplenomegalia. Con estos hallazgos se sospechó neoplasia linfoproliferativa o tuberculosis ganglionar.

Otros hallazgos fueron: lesiones en piel de tres años de evolución con diagnóstico de púrpura senil sin estudio histopatológico; consistentes con dermatosis diseminada simétrica, en dorso de manos, antebrazos y región medial de los pies (Figura 1 - Panel A), y placas purpúricas figuradas, infiltradas, de bordes irregulares y límites definidos, coloración irregular, no descamativas, sin signos clínicos de sobreinfección (Figura 1 -Panel B), además múltiples pápulas violáceas de superficie lobulada, dimensiones heterogéneas y una masa nodular eritematoviolácea, en región flexora radial de muñeca izquierda de 2 x $1.5 \mathrm{~cm}$ y telangectasias superficiales (Figura 2). A las impresiones diagnósticas previas se adicionó el SK por la apariencia de las lesiones cutáneas, y descartar la coexistencia de VIH por las manifestaciones sistémicas.

Se descartó la coinfección SK-VIH mediante: ELISA VIH no reactivo (2 pruebas), CD3: 1264 cel/uL, CD4: 796 cel/uL, CD8: $462 \mathrm{cel} / \mathrm{uL}$ y carga viral VIH no detectada. Los demás paraclínicos mostraron $\mathrm{Hb}: 10.2 \mathrm{gr} / \mathrm{dL}$, ferritina: $550.6 \mathrm{ng} / \mathrm{mL}$ ), ANAS y ENAS (sm, ro, la, rnp) negativos, VDRL no reactivo, proteína $C$ reactiva $40 \mathrm{mg} / \mathrm{dL}$, VSG 50 $\mathrm{mm} / \mathrm{h}$, creatinina $1.0 \mathrm{mg} / \mathrm{dL}$, AST $23 \mathrm{UI} / \mathrm{L}$ ALT $21 \mathrm{UI} / \mathrm{L}$. Mantoux: $0 \mathrm{~mm}$, albúmina $4.1 \mathrm{gr} / \mathrm{dL}$, electroforesis de proteínas séricas con hipergammaglobulinemia policlonal (alfa 1: $0.34 \mathrm{gr} / \mathrm{dL}$, gamma: $2.29 \mathrm{gr} / \mathrm{dL}$ ), inmunofijación de proteínas séricas no detectable. Anticuerpos anti-VHC negativo, HbsAg: negativo e IgM anticore: negativo, VEB IgM e IgG negativas. La tomografía computada (TC) de cuello, tórax y abdomen mostró adenomegalias múltiples de dimensiones variables, captación homogénea de contraste en zonas cervicales I a $\mathrm{V}$, región axilar e inguinal bilateral y esplenomegalia de $15,6 \mathrm{~cm}$ sin lesiones focales.

El informe de biopsia ganglionar cervical mostró arquitectura preservada, folículos linfoides secundarios (reactivos) de diferentes tamaños, centros germinales rodeados de linfocitos maduros dispuestos en capas concéntricas (piel de cebolla), estructuras vasculares de endotelio prominente que penetraban en el interior de los folículos y la pared reforzada por un material hialino, sin células plasmáticas en el espacio interfolicular, linfocitos B/CD20 positivo, sin coexpresión aberrante de BCL2. Células positivas para VHH -8. Con estos hallazgos se hizo el diagnóstico de ECM VHH-8 positivo de subtipo hialino-vascular. Biopsia de piel (Figura 3): células fusiformes, con imunohistoquímica positivas para CD31, CD34 y VHH-8 compatibles con SK. Niveles séricos de interleuquina 6 elevados: $4.47 \mathrm{pg} / \mathrm{mL}$ (Normal: $<3.4 \mathrm{pg} / \mathrm{mL}$ ).

Con el diagnóstico definitivo de SK y ECM/ VHH-8 positivo y VIH negativo se inició protocolo R-COEP (rituximab-ciclofosfamida-etopósido-prednisona). La serología para VHH-8 fue positiva (título 1/640 IFI) y carga viral de VHH -8 positiva $(145,513$ copias $/ \mathrm{mL})$ infectología inicia 
valganciclovir $900 \mathrm{mg}$ cada 12 horas por dos semanas y mantenimiento de $900 \mathrm{mg} /$ día. Después de ocho ciclos de quimioterapia alcanzó la remisión de las adenopatías y de las manifestaciones sistémicas, sin progresión de las lesiones del SK. A los seis meses de seguimiento la carga viral para VHH-8 fue indetectable.

\section{Discusión}

El interés de informar este caso de una mujer adulta mayor con diagnóstico de SK y ECM/VHH-8 positivo/VIH negativo está en resaltar el diagnóstico de estas dos entidades que por muchos años se diagnosticaron desde el punto de vista anatomopatológico y que hoy día representan un subgrupo etiológico claramente aceptado por la comunidad científica internacional como un subgrupo dentro del espectro clínico de las enfermedades asociadas al VHH-8 $(3,5)$.

Dicho espectro está conformado por la primoinfección por $\mathrm{VHH}-8$, que simula una mononucleosis infecciosa, y el SK, la ECM y el LPCS y otras patologías en donde se ha evidenciado el DNA viral como el pénfigo vulgar, mieloma múltiple, enfermedad de Kikuchi, sarcoidosis, entre otras (5). Las investigaciones sugieren que el virus es adquirido cerca de la adolescencia, puede transmitirse por varias vías, incluidos el contacto sexual, los hemoderivados, la saliva y posiblemente el trasplante de órganos (3).

La distribución de la infección por HVH-8 no es uniforme en la población mundial como la mayoría de los otros herpesvirus humanos (1). Varía ampliamente dependiendo de la región geográfica, la edad y del subgrupo (VIH positivos), la seroprevalencia aumenta para cada década de vida después de los 30 años (3). En adultos, es mayor en individuos del sexo masculino, homosexuales, drogadictos y trabajadores sexuales. Se observaron bajas tasas de seroprevalencia de VHH-8 (0-5\%) en el norte de Europa, Asia y América del Norte, tasas intermedias (5-20\%) Europa Oriental y el Caribe y altas tasas mayor de 50\% en África central y meridional (3, 6). Se han informado casos similares de SK y ECM / VHH-8 positivo/VIH negativo en Irán: varón de 77 años, con adenomegalias mediastinales, subpleurales y axilares, en nuestro caso fue en una persona de sexo femenino sin compromiso del mediastino ambos casos tenían lesiones cutáneas en extremidades inferiores (7). En 2006 en España se reportó un caso también de este subgrupo, masculino de 68 años, con hallazgo histológico del subtipo células plasmáticas, esto difería de nuestro reporte, además su tratamiento fue $\mathrm{R}-\mathrm{CHOP}$ y valganciclovir(8). Se identificaron tres reportes de casos de EC en Colombia, todos diagnosticados como ECU, VIH negativo, dos casos evidenciaron una lesión única cervical y el tercero tenía una lesión localizada en mama $(9-11)$.

Bajo el epónimo EC se cubre un grupo heterogéneo de entidades clínicas y anatomopatológicas. Casos como este deben motivar el desarrollo de un sistema de nomenclatura de enfermedades específicas, para definir los nombres que deben usarse para cada proceso etiopatológico (subgrupo etiológico) específicamente definido (12).

El SK y ECM/VHH-8 positivo / VIH negativo es una alteración infrecuente $(3,4)$. Es importante realizar un adecuado examen clínico y si los hallazgos sugieren una patología del espectro del VHSK, es imperativo realizar oportunamente biopsias con fines diagnósticos y serológicas para definir su presencia, nuestro medio tiene una tasa de prevalencia intermedia para VHSK y como se reportó no sólo afecta a individuos masculinos inmunosuprimidos.

\section{Referencias}

1. Schneider J. Diagnosis and Treatment of Kaposi Sarcoma. Am J Clin Dermatol. 2017;18:529-39.

2. Soulier J. Kaposi's Sarcoma-Associated Herpesvirus-Like DNA Sequences in Multicentric Castleman's Disease. Blood.1995; 86: 1276-80.

3. Matthew A. Human Herpesvirus 8-Related Diseases: Histopathologic Diagnosis and Disease Mechanisms.Seminars in Diagnostic Pathology 2017;4:1-4.

4. González A. Current diagnosis and treatment of Castleman's disease. Rev Clin Esp. 2016; 216: 146-56.

5. Ablashi D. Et Als. Spectrum of Kaposi's Sarcoma-Associated Herpesvirus, or Human Herpesvirus 8, Diseases. CLINICAL MICROBIOLOGY REVIEWS.2002; 15: 439-64.

6. Mohanna S, Maco V, Bravo F, Gotuzzo E. Epidemiology and clinical characteristics of classic Kaposi's sarcoma, seroprevalence, and variants of human herpesvirus 8 in South America: A critical review of an old disease. Int J Infect Dis. 2005;9(5):239-50.

7. Yaghoobi R. Co-existence of multicentric Castleman's disease and Kaposi's sarcoma. Eur Int J Dis-Case Report. 2015; 60: 323.

8. Pastor M. Dos enfermedades relacionadas con el VHH-8 en un paciente VIHnegativo: sarcoma de Kaposi y enfermedad de Castleman multicéntrica. Respuesta a tratamiento con Rituximab y CHOP. Actas Dermosifiliogr. 2006; 97(6): 385-90.

9. Sepúlveda M, Contreras E, Martínez N. Enfermedad de Castleman. Acta Med Colomb 2007; 32: 129-31.

10. Ochoa M, Herrera D, Dublin A, Sanabria A. Unicentric Castleman's disease in the posterior cervical space mimicking a schwannoma. European Annals of Otorhinolaryngology, Head and Neck diseases. 2016; 133: 191-19.

11. Rafael Parra-Medina, José Ismael Guio, and Patricia López-Correa. "Localized Castleman's Disease in the Breast in a Young Woman". Case Reports in Pathology. 2016; 16: 1-3.

12. Jennete $\mathbf{J}$ et al. Revised International Chapel Hill Consensus Conference Nomenclature of Vasculitides. Arthritis \& rheumatism. 2013; 65: 1-11 